\title{
Cuidado pastoral da Igreja em tempos de pandemia: Covid-19
}

\section{Pastoral care of the Church in pandemic times: Covid-19}

\section{Cuidado pastoral de la Iglesia en tiempos de pandemia: Covid-19}

\author{
Márcio Divino de Oliveira*
}

\begin{abstract}
RESUMO
O presente artigo reflete sobre o cuidado Pastoral da Igreja em tempos de Pandemia: Covid-19. Um tema atual e relevante, considerado os impactos que a pandemia tem trazido para a sociedade brasileira, assim como à pastoral da igreja nestes dias. Como a Teologia Pastoral faz correlação entre a fé e a realidade concreta, bem como propõe intervenções pastorais internas a igreja e junto a sociedade é importante examinar esse fenômeno. Os resultados da pesquisa, que tem como objeto de estudos as igrejas protestantes, indicam que a Covid-19 trouxe alterações não apenas no comportamento da sociedade e instituições, mas também à práxis pastoral da igreja: a inserção da pastoral online. Além disso, apresenta uma análise crítica do fenômeno e aponta caminhos para o exercício de uma pastoral online relevante nesse cenário.

Palavras-Chave: Pandemia; Covid-19; Teologia Pastoral; pastoral da Igreja; pastoral online
\end{abstract}

\begin{abstract}
This article reflects on the Pastoral care of the Church in Pandemic times: Covid-19. A current and relevant theme, considering the impacts that the pandemic has brought to Brazilian society, as well as to the pastoral of the church these days. As Pastoral Theology correlates faith and concrete reality, as well as proposing pastoral interventions that are internal to the church and to society, it is important to examine this phenomenon. The results of the research, which has as object of study the Protestant churches, indicate that Covid-19 brought changes not only in the behavior of society and institutions, but also in the pastoral praxis of the church: the insertion of pastoral online. In addition, it presents a critical analysis of the phenomenon and points out ways to exercise relevant online pastoral care in this scenario. Keywords: Pandemic; Covid-19; Pastoral Theology; pastoral of the Church; pastoral online.

RESUMEN

Este artículo reflexiona sobre el cuidado pastoral de la Iglesia en tiempos de pandemia: Covid-19. Un tema actual y relevante, considerando los impactos que la pandemia ha traído a la sociedad brasileña, así como a la pastoral de la iglesia en estos días. Como la Teología Pastoral correlaciona la fe y la realidad concreta, además de proponer intervenciones pastorales que son internas a la iglesia y a la sociedad, es importante examinar este fenómeno. Los resultados de la investigación, que tiene como objeto de estudio las iglesias protestantes, indican que Covid-19 trajo cambios no solo en el comportamiento de la sociedad y las instituciones, sino también en la praxis pastoral de la iglesia: la inserción de la pastoral en línea. Además, presenta un análisis crítico del fenómeno y señala formas de ejercer la pastoral en línea relevante en este escenario.
\end{abstract}

Palabras clave: Pandemia; Covid-19; Teología Pastoral; pastoral de la iglesia; pastoral en línea.

Docente na área de Teologia Pastoral, concentração em Missiologia, na Faculdade de Teologia da Universidade Metodista de São Paulo (Fateo/Umesp), mestre em Ciências da Religião (PPGCdR/ Umesp) e membro do Grupo de Pesquisa em Teologia Prática: Aconselhamento Pastoral (Umesp). 


\section{Introdução}

O ano de 2020 tem sido marcado pelo enfrentamento da Covid-19. Uma pandemia que teve início na China (comunicada oficialmente em 31 dezembro de 2019) e assola diferentes países do mundo. O Brasil, desde o dia 26 de fevereiro 2020, quando oficialmente foi anotado o primeiro caso (MINISTÉRIO DA SAÚDE, 2020, n.p.), tem registrado inúmeros casos e mortes de pessoas pelo novo coronavírus: Covid-19.

Segundo a historiadora Lilia Schwarcz a pandemia Covid-19 é o marco que a humanidade esperava para registrar, em forma de experiência marcante - não simplesmente evento cronológico -, o fim do século XX e a entrada no século XXI (apud BRANDALISE; ROVANI, 2020, n.p.). Para a historiadora o século XX foi um período de "grande desenvolvimento tecnológico, mas agora a pandemia mostra esses limites" (apud BRANDALISE; ROVANI, 2020, n.p.). Schwarcz sugere ainda que esses dias de pandemia serão lembrados pelos livros de história como "o dia que a terra parou" (apud BRANDALISE; ROVANI, 2020, n.p.).

Todavia, é preciso acompanhar melhor os desdobramentos da pandemia nos diferentes setores da vida humana (ciência, economia, política, cultura, social, religiosidade, etc.) para confirmar ou não essa teoria. O certo é que em meio a pandemia Covid-19 observa-se profundas mudanças no comportamento social dos/as brasileiros/as, procedimentos institucionais e de empresas, assim como nas práxis pastorais das Igrejas nesse período crítico de saúde pública.

Compreender os impactos dessas mudanças na práxis pastoral da igreja é importante para a Teologia Pastoral, setor da Teologia que articula a correlação entre a fé/Evangelho e a realidade cotidiana; a práxis da igreja à suas ações internas e as situações concretas da sociedade (COSTAS, 1975, p. 109-102; SATHLER-ROSA, 2004, p. 67.). De igual modo, pensar novas formas de ação pastoral nesse tempo de pandemia se impõe como imperativo à pesquisadores da Teologia Prática ${ }^{1}$, às lideranças pastorais e às igrejas. Neste sentido, o presente artigo faz esse percurso e exercício metodológico, privilegiando como objeto de estudo as Igrejas de Tradição Protestante.

Antes de aprofundar a análise e as discussões sobre a pastoral em tempos de pandemia: Covid-19, indica-se que o presente artigo privilegiou autores

\footnotetext{
O autor reconhece as divisões clássicas entre Teologia Prática e Teologia Pastoral. Como são áreas correlatas, suas contribuições teóricas são assumidas amplamente neste artigo na construção de uma pastoral da Igreja em tempos de Covid-19. Os conceitos de Teologia Pastoral e de Pastoral são assumidos em perspectiva latino-americana, considerando os referenciais teóricos de: COSTAS, 1975; FLORISTAN, 1993; CASTRO, 2000; SATHLER-ROSA, 2004
} 
especialistas da Teologia Pastoral e áreas correlatas. Como as pesquisas sobre o tema, na área de Teologia Pastoral, ainda estão em curso, foram realizadas consultas em sites, revistas e jornais e os dados analisados criticamente à luz da Teologia Pastoral.

Que a presente pesquisa ajude na construção de novos saberes, assim como ilumine a práxis teológica e a ação pastoral da igreja nesse momento crítico de pandemia.

\title{
A globalização do medo invisível: o Brasil e a pandemia Covid-19
}

O mundo globalizado tem sido marcado não só pela integração de povos e países em escala mundial, em seus diferentes setores (social, cultural, político, econômico, epistemológico, tecnológico, religiosos, etc.), mas também pela socialização do medo (BAUMAN, 2018, p. 172). O sofrimento, catástrofes e/ou crises ambientais (entre outras situações) não tem impacto apenas local, mas também implicações em escala global. Inclusive podendo ser acompanhado por diferentes pessoas e povos mundialmente, por meios das novas tecnologias digitais.

Assim, o que acontece em um país pode trazer impacto a outros povos e/ou nações, tal como a proliferação de vírus e doenças, devido ao grande fluxo de pessoas viajando pelo mundo afora, seja em turismo ou negócios. Deste modo, vive-se nesses tempos globalizados ambientes propícios para proliferação de vírus/doenças e surgimento de pandemias. A propósito desse último tema, o ano de 2020, como já indicado, tem sido marcado pelo avanço alarmante do novo coronavírus (Covid-19), uma doença que surgiu na China e se espalhou rapidamente mundo afora causando inúmeras infeções e mortes.

Segundo Lima:

\begin{abstract}
Os coronavírus são uma grande família viral, conhecidos desde meados de 1960, que causam infecções respiratórias em seres humanos e em animais. Geralmente, infecções por coronavírus causam doenças respiratórias leves a moderadas, semelhantes a um resfriado comum. Alguns coronavírus podem causar doenças graves com impacto importante em termos de saúde pública, como a Sars (Síndrome Respiratória Aguda Grave), identificada em 2002 e a Mers (Síndrome Respiratória do Oriente Médio), identificada em 2012 (LIMA, 2020, p. 5).
\end{abstract}

Como se nota, o coronavírus tem muitas famílias, sua atual versão recebe o nome de Covid-19, em substituição ao nome provisório 2019-nCoV, de difícil pronúncia. Chegou-se a esse nome a partir da seguinte construção: "Co" significa corona, "vi" vem de vírus, e "d" representa "doença”. Já o número 19 indica o ano de sua aparição, 2019 (VIVABEM, 2020, n.p.) 
O Brasil vive um momento delicado, desde que a Covid-19 chegou no país e se alastrou rapidamente, alterando sensivelmente a vida dos brasileiros, sobretudo, a partir do mês de março 2020, provocando muitos contágios e mortes. Para se ter uma ideia, o número de infectados já ultrapassou a marca de 90 mil casos e 6 mil mortos - no momento em que esse texto é revisado para publicação $(01 / 05 / 2020)$ - e, infelizmente, só cresce em meio a suspeitas de subnotificações dos dados da Covid-19 (SAVIANO, 2020, n.p.; VENAGLIA, 2020, n.p.).

O vírus avança no país tendo a seu favor os problemas estruturais conhecidos: fragilidades no sistema de saúde, dramas sanitários e sociais, má distribuição de benefícios sociais; deficiências na articulação entre esferas do governo federal, estadual e municipal, etc. Soma-se a isso a polarização entre o fator econômico e as políticas de isolamento social; crises políticas; problemas diplomáticos; demissão do ministro da saúde em meio a luta contra a pandemia; pressão de setores das igrejas evangélicas para manter templos abertos durante o crescimento no número de casos da Covid-19 no país; o fenômeno da negação da gravidade da pandemia e a proliferação de fakenews - ajudando no afrouxamento do isolamento -; pouca agilidade do governo federal na gestão de momentos de crises; entre outros problemas (CUNHA, 2020, n.p.; FERRARI; CUNHA, 2020, n.p.; SILVA, 2020, n.p.)

Entre a população de risco, estão as pessoas acima dos 60 anos, pessoas abaixo dessa faixa de idade com comorbidades, grávidas e puérperas (PINHEIRO, 2020, n.p.; SOUPIN, 2020, n.p.). Representantes das áreas da saúde projetaram os meses de abril, maio e junho 2020 como períodos críticos da pandemia no Brasil, podendo o vírus circular no país até o mês de setembro 2020 (COLETTA; URIBE, 2020, n.p.). Daí várias medidas têm sido realizadas: isolamento social, restrição à setores comerciais, reestruturação do setor de saúde pública para atendimentos aos casos, entre outras. Por iniciativa de alguns campos, muitas empresas têm trabalhado em sistema home-office. Além de mudanças comportamentais individuais e coletivas sociais nesse período.

Os mortos pela pandemia, em várias partes do país têm sido enterrados sem a presença de seus familiares. Assim, famílias choram a morte de seus entes queridos, convivem com o luto (alguns traumáticos) e com a dor de não poderem se despedir dignamente de seus familiares mortos (PAES, 2020, n.p.). Essa situação, aliada aos noticiários diários de mortes e a política de isolamento social (necessária, segundo OMS), pode fazer crescer os sintomas das doenças mentais entre a população: ansiedade, depressão, angústia, síndrome do pânico, entre outras (COSTA, 2020, n.p.; SPONCHIATO, 2020, 
n.p.). Em outros termos, a pandemia levanta a preocupação não apenas com a saúde física das pessoas, mas também com a saúde emocional - e, porque não afirmar também, a saúde espiritual.

A Igreja Cristã possui uma rica tradição de cuidado e suporte às pessoas em meio a momentos críticos e de crises da vida (CLINEBELL, 1998, p. 14; SATHLER-ROSA, 2004, p. 72). Afinal de contas, firmada na fé em Cristo, o Bom-Pastor, a igreja ao longo de sua história, em diferentes momentos demonstrou compaixão e solidariedade às pessoas que sofriam: catástrofes naturais/ambientais, pandemias, guerras, crises financeiras e de fome, etc.

Deste modo, neste cenário delicado em que vivemos, recobra a importância de se pensar a práxis pastoral da igreja a fim de ajudar as pessoas em meio à pandemia do Covid-19. A Teologia Pastoral pode operar valioso papel à igreja nesse momento: subsidiar suas práxis pastorais. A seguir, apresenta-se análise e o papel da práxis pastoral em tempos de crises e mudanças.

\section{Pastoral em tempos de crises: momento de ressignificação}

O termo pastoral aqui aplicado não se refere apenas ao pastor ou à pastora, mas à ação do povo de Deus (incluindo clérigos e leigos, a igreja corpo vivo de Cristo), que, em sentido amplo, busca cuidar/pastorear as pessoas e a sociedade em seu cotidiano, sobretudo, em tempos difíceis (COSTAS, 1975, p. 109-102; SATHLER-ROSA, 2004, p. 54). Afinal de contas, a igreja, seguindo as pegadas de Jesus (Bom-Pastor), pastoreia e faz isso por meio de diferentes vocações: ministério ordenado (pastor/a) e ministérios exercidos por leigos.

De acordo com Sathler-Rosa (2004, p. 55), a "ação pastoral, por meio do laicato e de pessoas ordenadas, procura trazer para o concreto e provisório da vida humana o efeito do encontro com a Verdade, o Cristo". Nesse sentido, a ação pastoral alcança o cotidiano das pessoas nas suas mais diferentes esferas de vivência: na alegria, na tristeza, da dor, na saúde, na perda, no ganho, etc. Isso inclui pensar a ação pastoral tanto para dentro quanto fora da igreja. Sobre isso, Castro lembra que (2000, p. 105) “a preocupação básica da pastoral é a eficácia e a relevância da fé cristã. Pastoral é também responsável pela inserção do povo de Deus no espaço público", algo urgente nesses tempos de insegurança.

Antes de avaliar algumas ações pastorais possíveis nesse momento, é importante compreender que o mundo passa por mudanças. Não só pelos profundos processos epistemológicos, tecnológicos e sócio-políticos ocorridos nas últimas décadas (GADOTTI, 2000, p. 3; CASTELLS, 2002, p. 67-71; 
BAUMAN, 2007, p. 7), mas pelo momento crítico que vivemos, dado ao enfrentamento da pandemia Covid-19. Analistas, de diferentes áreas, afirmam que o mundo e a humanidade não serão os mesmos após essa pandemia (OLIVEIRA, 2020a, n.p.).

Neste cenário, a economia e diferentes setores mercadológicos e institucionais têm se reinventado, sobretudo, potencializado pelas novas ferramentas digitais. No campo da Teologia Pastoral não é diferente. Como área da teologia que buscar refletir sobre a práxis da igreja e sua correlação com o cotidiano (COSTAS, 1975, p. 109-102; SATHLER-ROSA, 2004, p. 67; CASTRO, 2000, p. 105), nota-se a necessidade da ressignificação das tradicionais práxis pastorais da igreja nesse período. Assim, neste contexto de Covid-19 e política de isolamento social, a Teologia Pastoral nos ajuda a compreender a importância do uso das novas tecnologias de informação e comunicação (internet, ferramentas virtuais, redes sociais, etc.) na práxis pastoral da igreja.

Isso não exclui outras formas de atuação pastoral. Todavia, a busca por alternativas criativas de ação pastoral da igreja, otimizadas pelos recursos online/virtuais, demostram ser uma decisão adequada para esse tempo de pandemia. E poderá ser por um significativo período, mesmo com a flexibilização da política de isolamento social, considerando que o vírus continuará a circular no país por um bom período. E essa pandemia alterará profundamente o modo de convivência pública das pessoas. Portanto, a igreja poderá ainda conviver com a insegurança das pessoas quanto à presença em cultos e outras atividades religiosas.

Por isso, discernimento e prudência são virtudes requeridas por parte de igrejas e líderes pastorais nesse momento. A julgar pelo perigo de contágio, por parte de pastores/as e/ou leigos/as no cuidado às pessoas. Assim como o risco de cuidadores pastorais infectarem fiéis e/ou seus familiares em suas atividades ministeriais. A morte de mais de 60 Padres italianos no cuidado de enfermos e a notícias da morte de alguns pastores/as nesse período corrobora com essa preocupação (UOL, 2020, n.p.).

A propósito do tema do discernimento e prudência no exercício da práxis pastoral em tempos de pandemia, é oportuno recordar uma orientação do reformador protestante, Martinho Lutero, escrita em 1527 e dirigida ao pastor Johannes Hess, durante a pandemia da "Peste Negra" que ceifou milhares de vidas na Europa. Apesar do distanciamento histórico, suas orientações apontam horizontes pastorais valiosos para esse momento. Escreve, Lutero:

Pedirei a Deus para, misericordiosamente, proteger-nos. Então farei vapor, ajudarei a purificar o ar, a administrar remédios e a tomá-los. Evitarei lugares e pessoas onde minha presença não é necessária para não ficar contaminado e, assim, porventura in- 
fligir e poluir outros e, portanto, causar a morte como resultado da minha negligência. Se Deus quiser me levar, ele certamente me levará e eu terei feito o que ele esperava de mim e, portanto, não sou responsável pela minha própria morte ou pela morte de outros. Se meu próximo precisar de mim, não evitarei o lugar ou a pessoa, mas irei livremente conforme declarado acima. Veja que essa é uma fé que teme a Deus, porque não é ousada nem insensata e não tenta a Deus (LUTERO, 1968, p. 116).

Chama a atenção no texto a conexão de Lutero com uma espiritualidade responsável no lidar com a pandemia de seu tempo. Assim como seu esforço por entender seu contexto, a fim de propor uma pastoral relevante para aqueles dias. Neste sentido, cabe a Igreja - por meio de seu ministério ordenado e leigo - fazer leituras da realidade presente e pensar ações pastorais propícias para esse momento de enfrentamento da pandemia Covid-19 no Brasil. A seguir, apresentamos algumas possibilidades!

\section{Práxis pastoral em tempos de Covid-19: exame de possibilidades}

\section{Uma pastoral de cuidado online: igreja e a sociedade}

Como indicado, o tempo presente é ímpar na história. Considerando que pastores/as, assim como cristãos dedicados ao cuidado de pessoas, acostumados a realizar as tarefas poimênicas ${ }^{2}$ de modo presencial (CLINEBELL, 1998, p. 25; SCHNEIDER-HARPPECHT, 1998, p. 291-319) se veem nesse momento tendo que buscar alternativas para o cuidado pastoral por meios online. Isto é, a mediação das novas tecnologias de comunicação e informação (TICs): telefone, celular, internet, rede socais: whatsapp, facebook, instagram, skype, entre outras ferramentas digitais. Uma decisão acertada e sábia da igreja nesse período difícil (CUNHA, 2020, n.p.; IGREJA METODISTA, 2020, n.p.; IECLB, 2020, n.p.; ALIANÇA EVANGÉLICA, 2020, n.p.).

Assim, as tradicionais atividades e práxis pastorais da igreja (cultos, Ceia do Senhor, oração; atendimento e aconselhamento pastoral; visita pastoral, pregações e mensagens bíblicas de esperança; oficio fúnebre, etc.) são reinventadas por meio das ferramentas virtuais nesse período. Alternativas para cuidar pastoralmente das pessoas enfermas e o povo que chora nessa situação crítica - tanto da igreja quanto da sociedade. De igual modo, novas formas de ações pastorais nascem nesse tempo de poimênica digital. Como, por exemplo, a produção de "Webinário, Webconferência" e "Lives" realizadas por líderes pastorais (pastores/as e/ou leigos/as com ministérios distintos)

\footnotetext{
2 A palavra poimênica e suas variações, utilizadas nesse texto (poimênico e poimenicas), compreende " o ministério amplo e inclusivo de cura e crescimento mútuo dentro de uma congregação e de sua comunidade, durante todo o ciclo da vida" (conf. CLINEBELL, 1998, p. 24).
} 
com vista a estabelecer uma comunicação dialógica, próxima e cuidadora das pessoas em tempos de confinamento e sofrimento.

Chama-se a atenção para o fato de que alguns setores das igrejas protestantes brasileira já estavam integrados a mídia e as ferramentas digitais. Um fenômeno diverso e plural, amplamente pesquisado por estudiosos das áreas de comunicação, teologia e ciências da religião interessados na relação "igreja e a mídia na sociedade do espetáculo" (MIKLOS, 2012, p. 29; RAMOS, 2010, p. 181-188). Todavia o fenômeno em curso apresenta características diferentes. Surge das demandas atuais, o desafio de produzir práxis pastorais (cuidado as pessoas da igreja e da sociedade) em tempos de pandemia e de política de isolamento social. Se essas ações alterarão substancialmente o(s) paradigma(s) da práxis pastoral da igreja em um futuro próximo, não é possível concluir ainda. Urge acompanhar atenciosamente os desdobramentos dessas ações no cotidiano da igreja.

Avaliando essas práxis à luz de conceitos da Teologia Pastoral, Floristan (1993, p. 179-180) lembra que a igreja exerce sua práxis pastoral de forma criativa, reflexiva, crítica, transformadora e radical. Isso permite compreender que os usos das ferramentas digitais não podem ser simplistas - uma mera replicação das tradicionais formas de cuidado no espaço virtual -, mas realizada de forma crítica e criativa para alcançar eficientemente as pessoas. Afinal de contas, os meios digitais operam em uma outra lógica, diferente das dinâmicas presenciais. Daí a necessidade de conhecer bem cada plataforma ou ferramenta digital para o êxito da elaboração dos conteúdos digitais e sua veiculação, bem como não saturação das pessoas receptoras desses conteúdos online.

Além disso, como a práxis pastoral é crítica, reflexiva, transformadora e radical, a igreja não pode cair na tentação do uso dos meios digitais de forma exploratória (ganho com o medo e insegurança das pessoas), como fazem alguns setores religiosos insensíveis ao sofrimento humano. A igreja existe no mundo (seja presencial e vitualmente) para ser testemunha da graça, do amor e da misericórdia de Deus, assim como para lutar pela implementação de sua justiça na sociedade. De igual modo, a igreja precisa também ter cuidado no uso dos meios digitais, como portadora de uma práxis pastoral crítica e reflexiva, para não ser utilizada na proliferação de "fake news" ou repetir ideologias dominadoras.

Ressalta-se que esse momento deve ser uma rica oportunidade não só para atuação do/a pastor/a nas ações ministeriais online, mas para a integração de todas as áreas da igreja nas práxis pastorais - pois como indicado acima, pastoral incluí todo o povo de Deus. Ademais, é uma ótima oportunidade 
para a área da comunicação da igreja colocar em ação alguns de seus planos para esse setor e otimizar a vida e missão da igreja.

Em termos futuros, reafirmamos que, à medida que acontecer a flexibilização da política de isolamento e volta gradual de cultos presenciais, será necessário ter cuidado com a reaproximação social. Além do mais, como nem todo grupo de pessoas poderá frequentar o culto, será interessante equilibrar as ações: culto presencial com distanciamento social e transmissão de cultos online, entre outras ações, para quem não puder participar.

Por fim, os conhecimentos e a expertise adquirida com o uso dos meios virtuais/online nesse período não podem ser desprezados quando a pandemia passar. Afinal de contas, o século XXI é digital e habitado por inúmeros indivíduos, portanto, esse espaço e meios digitais devem ser assumidos pela pastoral da igreja como forma de cuidado às pessoas nesses tempos da informação e comunicação. Uma rica oportunidade para a integração crítica, reflexiva e eficiente das novas tecnologias digitais à práxis pastoral da igreja, como forma de cooperar na missão de Deus.

\section{Uma pastoral de cuidado a profissionais de saúde e demais profissionais dos} serviços essenciais

$\mathrm{Na}$ frente da batalha, inúmeros profissionais de áreas dos serviços essências (médicos, policiais, profissionais de supermercados, caminhoneiros, etc.) que lutam bravamente para proteger vidas e manter a "normalidade" em tempos de insegurança. Todavia, esses trabalhadores, além de conviverem com o perigo da morte, enfrentam duras situações de estresses e preocupações com seus familiares. É importante que a igreja busque formas de alimentar espiritualmente e pastorear esse grupo nesse momento.

Esse tipo de apoio pastoral ocupa um significado especial na vida dos profissionais de saúde. Isso porque, além de apresentarem necessidades de cuidado como qualquer pessoa, os médicos/representantes da saúde são formados para salvar vidas. A morte de seus pacientes pode trazer sofrimentos e conflitos a esses profissionais (KOVÁCS, 2004, p. 283-285). Sem esquecer o fato de conviverem, nesse momento de pandemia, mais do que outras épocas; com jornada estressante de trabalho, risco de contaminação pelo vírus, pelas faltas de infraestrutura adequada de trabalho; e preocupação com os familiares, como já indicado, entre outras situações. Indicações que mostram o quanto uma pastoral de cuidado com profissionais de saúde recobre-se de significado neste cenário.

As ferramentas digitais podem ser um caminho, como indicado acima, para pastorear esses profissionais. Além disso, a capacitação de profissionais 
cristãos que trabalham nesses setores para nutrir seus colegas aparece como outra alternativa possível nesse período. Por fim, pastores/as podem construir devocionais e mensagens voltadas a esses profissionais para sustentá-los/ as via grupos virtuais e/ou redes social. E, se encontrar formas seguras de proteção à saúde (pessoal e coletiva), pastores/as podem também propor devocionais e orações com esses profissionais presencialmente.

\section{Uma pastoral solidária e compassiva}

Os templos das igrejas estão de portas fechadas, mas não a igreja orgânica - corpo vivo de Cristo, formado por fiéis discípulo/as. Deste modo, essa é uma especial oportunidade do exercício da solidariedade, ajuda aos mais carentes da comunidade de fé. Todavia, a solidariedade da igreja não pode encerrar apenas no auxílio aos domésticos da fé. Ações mais amplas devem ser realizadas em prol da ajuda às pessoas necessitadas da sociedade (conf. CASTRO, 2000, p. 110). Afinal de contas, muitas são as pessoas que perderam seus empregos ou não poderão exercer suas atividades, por serem autônomos. Sem esquecer dos representantes da população vulnerável (a população de rua, crianças vulneráveis, imigrantes, presos, etc.) com sua assistência comprometida nesse momento.

É verdade que as situações econômicas têm atingido as igrejas, todavia essa realidade não pode impedir a igreja de ser presença solidária de Deus com os que choram. Urge pensar ações criativas nesse tempo para ajudar àqueles que sofrem. Nesse sentido, as igrejas podem criar ou apoiar redes solidárias; ajudar instituições humanitárias com experiências neste campo. Também mobilizar os membros da igreja para apoiar seus vizinhos idosos ou pessoas do grupo de riscos que precisam de auxílios nesse momento, por não poderem circular - exemplo, na elaboração de compras em supermercados, entre outras ações. De igual modo, confeccionar máscaras de proteção para distribuir às pessoas de riscos ou profissionais dos serviços essenciais.

Por fim, as igrejas podem disponibilizar suas instalações ao poder público para participar de ações diversas nesse momento. Afinal de contas, pode ser que alguma igreja tenha suas instalações em pontos/bairros estratégicos de combate à pandemia. Deste modo, a igreja pode ser um posto de vacinação (gripe); local de cadastramento de famílias beneficiárias dos sistemas governamentais de auxílio social; ponto de distribuição de cestas (governo ou ONGs), entre outras possibilidades. Destaca-se que esse compromisso diaconal da igreja nesse tempo não pode ser desassociada da dimensão profética da pastoral: luta pela justiça e transformação social! 


\section{Uma pastoral às familias em tempos de confinamento}

A pandemia impôs novas dinâmicas às famílias, já que, em sua maioria, os membros da família estão reunidos, confinados em casa. Com isso, os pais, acostumados a pouca convivência com os filhos, agora se veem diante da relação diária com eles e vice e versa. Tendo que dividir suas tarefas profissionais com a educação, diversão e atenção aos filhos. De igual modo, os cônjuges se veem diante da tarefa de reinventar-se para dar conta das tarefas domésticas, trabalhos, criação dos filhos e a relação nestes tempos líquidos (COSTA, 2020, n.p.).

Outras configurações familiares, hoje reconhecidas, também vivem suas crises nesse momento de família confinada. Inclusive se assiste neste período movimentos de casais separados, reconfigurando suas rotinas (guarda compartilhada) e, em alguns casos, voltando a morar juntos com seus antigos parceiros para cuidarem dos filhos (LEITE; 2020, n.p.; GONTIJO, 2020, n.p.). Na esteira das crises enfrentadas pelas famílias, nesse tempo de pandemia, temos as crises vivenciadas por famílias que nem começaram ainda: casais de noivos que tinham seus casamentos marcados para esse período (CAFARDO; 2020, n.p.; NEVES, 2020, n.p.).

Especialistas afirmam que esse tempo é uma rica oportunidade para as famílias reaprenderem a conviver, crescerem na crise/adversidade e ressignificarem dimensões relacionais: afeto, comunicação, cordialidade, valores, prioridades, espiritualidade, dentre outras (COSTA, 2020, n.p.; OLIVEIRA, 2020 b, n.p.). Salienta-se que a igreja tem uma rica tradição de cuidado, orientação e enriquecimento poimênico, às famílias, sobretudo, em tempos de crises (CLINEBELL, 1998, p. 251-252). O cenário indica que a construção de uma pastoral familiar, nestes tempos de pandemia, ganha uma relevância singular: ajudar as famílias nesses tempos de medo e confinamento.

Vale destacar que uma pastoral da família relevante para esse cenário de pandemia e confinamento, além de compreender a complexidade da(s) identidade(s) familiar(es) na atualidade, precisa também dar atenção às suas particularidades. Por exemplo, tempos de confinamento são propícios para o surgimento ou intensificação de distúrbios psíquicos: quadros depressivos, ansiosos e compulsivos, estresses, etc. (SCHMIDT et al., 2020). Cada membro da família pode lidar com esses dramas psíquicos de formas diferentes. E o agravamento de algum desses quadros psíquicos pode causar mudanças de humor, da percepção e do comportamento alterando as dinâmicas relacionais familiares e, por consequência, produzir conflitos no interior da família (OLIVEIRA, 2020b, n.p.). 
Além disso, tempos de confinamento podem despertar manias, o consumo exagerado de bebidas alcoólicas, hipocondria, reacender problemas relacionais latentes, bem como ser cenário propício para a potencialização de abusos e/ou de violências familiares. Aliás, a ONU chama a atenção para o crescimento de violência doméstica de gênero em alguns países que enfrentaram a Covid-19 (China, Canadá, Espanha, Estados Unidos, entre outros), inclusive, o Brasil (FOLHA DE SÃO PAULO, 2020, n.p.). Vieira (et al., 2020, p. 2-3) confirma o aumento de casos de violência doméstica contra as mulheres em contexto brasileiro. $\mathrm{O}$ que nos coloca em alerta não apenas para gravidade do assunto (violência contra a mulher), mas ao risco de aumento do feminicídio nesse período.

A compreensão dessa realidade ajuda a igreja produzir uma pastoral contextual e relevante para esse momento. Do contrário, corre-se o risco de repetir uma pastoral fundamentalista, moralista e insignificante para o cenário. Neste empreendimento, a igreja pode se utilizar dos canais online para realizar diferentes ações pastorais com as famílias em tempos de pandemia, a saber:

1. Lives e/ou Palestras virtuais sobre família em dias de confinamentos;

2. Aconselhamento Pastoral familiar virtual (individual e em grupo);

3. Pregações e mensagens virtuais voltadas as famílias;

4. Palestras virtuais: 1. Confinamento e saúde psíquica; 2. Confinamento e dependência química (alcoolismo); 3. Lares sem violência: em tempos de confinamento; 4. Espiritualidade em tempos de pandemia e confinamento; etc.

5. Pastoral especifica de suporte e apoio a mulheres que sofrem violência doméstica;

6. Aconselhamento Pastoral Especifico com Noivos: a crise de adiar sonhos - casamento;

7. Vídeos com orientações gerais sobre cuidados preventivos à Covid-19;

8. Entre outras ações.

Concluindo, ressaltamos que a igreja, a partir de sua ação pastoral, pode fornecer importantes contribuições para ressignificação das famílias nestes tempos de pandemia e confinamento. Momento em que famílias experimentam medos, crises e desafios relacionais. Para tanto, como indicado, precisa investir na compreensão de sua tradição de cuidado e das configurações das famílias nesse tempo de pandemia. 


\section{Uma pastoralaosenlutad@s}

Como salientado, o país está comovido, contando seus mortos diariamente. Fora isso, os familiares das vítimas do novo coronavírus vivem o vazio de não poderem enterrar seus mortos - prestar-lhes as justas homenagens (PAES, 2020, n.p.). O sentimento de luto é geral, tanto para quem perde seus queridos pelo Covid-19 quanto para quem vê a contagens dos mortos na televisão.

Soma-se a isso os outros lutos que esse momento trás, a saber luto pela: perda do emprego; queda na renda e/ou nos negócios; perda da mobilidade; falta de sentido de futuro/esperança; saudade da convivência com avós, netos, amigos/as e vice-versa; entre outros. Isso tudo cria um sentimento de impotência e vazio existencial às pessoas.

Essa realidade recobra a necessidade da igreja pastorear não apenas os enlutadas, mas uma sociedade em luto. Segundo Paula (2010, p. 121), "como terapêutica, a presença da comunidade na vida de enlutados/as pode contribuir de forma significativa para a saúde das pessoas ao vivenciarem uma perda", na operação de seus lutos. Apesar de não poder se reunir nesse momento, há muitas formas de ser comunidade de fé conectada e ressignificar a presença da igreja junto as pessoas enlutadas neste cenário: os meios digitais são um caminho.

A realização de Ofício Fúnebre (virtual) nesse momento e/ou de culto In Memoriam presencial quando terminar o isolamento, pode oferecer valiosos confortos às famílias enlutadas. $O$ fomento de espaço de escuta ou criação de grupos de apoio de luto virtuais aparecem como ações pastorais valiosas nesse contexto. Igualmente, a construção de mensagens cristãs abordando o tema da espiritualidade diante da morte e do luto se reveste de significado para a pessoa enlutada, pois nessas situações emergem inúmeras perguntas e dúvidas. Soma-se a isso o destaque às pessoas enlutadas do papel consolador e sustentador do Espírito Santo nesses momentos de dor (conf. PAULA; 2010, p. 119-126).

\section{Uma pastoral de sentido e esperança}

A espiritualidade reforça na pessoa a confiança nas energias regenerativas da vida (BOFF, 2013, n.p.). Afinal de contas, a fé cristã é fonte de horizonte de sentido e esperança realista. Isto ganha significado em tempos difíceis, em que o sentimento de medo e insegurança toma conta das pessoas. Uma análise teológica-pastoral e social desse momento, bem como reflexões sobre horizontes futuros do país indicam que as crises existenciais podem acompanhar as pessoas por um longo período. Nesse contexto, urge a necessidade 
da construção de uma pastoral de sentido e esperança para nutrir as pessoas e a sociedade brasileira.

Assim, cabe à igreja e seu corpo pastoral fazer leitura do cenário atual e futuro; reconhecer o mundo como sua paróquia e propor pastorais contextualizadas para cada momento e circunstância. Isso exigirá da igreja sensibilidade, busca por renovação e fomento de uma pastoral criativa. Todavia, sem deixar de compreender que em tempos de crises, orientada pela fé em Cristo, a igreja é chamada a cuidar das pessoas e nutrir nelas as forças resilientes e espirituais potencializadoras da vida (CLINEBELL, 1998, p. 178-199; OLIVEIRA; NOGUEIRA, 2010, p. 4).

A título de exemplo, os músicos e grupos de música/corais das igrejas, guiados por uma pastoral solidária, poderiam pensar caminhos para fomentar, nos espaços cotidianos, músicas e hinos cristãos clássicos, fortalecedores de fé e esperança. Sem criar constrangimentos ambientais ou riscos às vidas quanto à circulação do vírus. Alguns músicos cristãos têm se utilizado das plataformas virtuais para esse tipo de ações. Laudenir (2020, n.p) indica em reportagem que a música é um importante aliado das pessoas no enfrentamento do isolamento social. A quantidade de "lives" produzidas neste período e a corrida do público para acompanhá-las pode ser um indicativo desse fenômeno durante a pandemia.

Enfim, a igreja precisa ler a realidade e propor pastorais criativas para esses tempos críticos: presente e futuro. Uma pastoral que seja fortalecedora e orientadora das pessoas quanto a seu sentido de vida e construtora de sementes de esperança no cotidiano. Isso tem um valor ímpar tanto para as pessoas que lutam contra a enfermidade Covid-19 quanto para suas famílias e a sociedade imersa no medo. Assim como para os profissionais das áreas dos serviços essenciais que enfrentam diariamente a pandemia. As alternativas são infinitas, uma igreja relevante na sociedade não ignora esses momentos: dá testemunha de sua fé e esperança no mundo.

\section{Uma pastoral profética}

Os tempos de crises, como esse de pandemia, são momentos de muita insegurança, distorções e ebulição de vozes dissonantes à vida. Discursos econômicos predatórios e anti-vida prevalecem! É preciso discernimento espiritual para reconhecer a voz de Deus nesse cenário para não cair nas armadinhas político-ideológicas, entre outras. Orientada pelo evangelho, a Igreja em missão não pode esquecer de sua tarefa profética no exercício da pastoral (conf. FLORISTAN, 1993, p. 179-180; CASTRO, 2000, p. 120-121).

Neste contexto, a igreja pode atuar profeticamente em termos amplos. Por exemplo, em um cenário de pandemia, em que reina o individualismo, é 
tarefa da igreja ajudar a sociedade na construção de uma consciência coletiva preventiva. À luz do evangelho, chamar as pessoas à conversão de um pensamento individualista para um pensamento e comportamento comunitário. Nessa direção, a igreja pode usar os seus meios de comunicação (digitais) para fortalecer as políticas de isolamento social, medidas que visam diminuir a circulação e contágio do vírus entre a população e sobrecarga do sistema público de saúde.

A igreja pode também fortalecer a consciência da população, sobretudo das pessoas que possuem melhores condições econômicas, quanto à importância de não abusarem nas compras ou fazerem estoques desnecessários. Para não contribuírem com a escassez de produtos nos supermercados e, consequentemente, comprometer a vida de outras pessoas - em particular, daqueles que têm menor poder econômico. Além disso, é momento de despertamento de consciência solidária. Como indicado acima, a igreja pode promover campanhas e/ou participar de redes que incentivem indivíduos e empresa a práticas solidárias a pessoas ou famílias vulneráveis.

As igrejas podem ainda, a partir de esferas/organismos coletivos de que participam, criar, nas cidades em que atuam, fóruns virtuais de debates sobre o papel pastoral da igreja em tempos de pandemia e pensar ações conjuntas - durante e pós Covid-19. As igrejas podem, também, participar de fóruns governamentais, de empresas ou de instituições do terceiro setor que debatem desafios sociais (locais, estaduais e nacionais) nesse momento de pandemia (e pós Covid-19) e ajudar nas soluções/encaminhamentos. Assim como apoiar os projetos criados por estes organismos, inclusive incentivando os fiéis a participarem desses espaços.

Nesta direção, as igrejas podem produzir seminários virtuais que ajudem os cristãos a entenderem sua vocação para uma fé pública/fé cidadã (CASTRO, 2000, p. 107), como parte de seu engajamento na missão de Deus, a partir de suas formações e profissões neste tempo de combate à pandemia Covid-19 - e em outros momentos da vida da sociedade.

Somam-se a essas ações proféticas, os esforços das igrejas em fomentar em suas instituições teológicas encontros, debates e congressos virtuais teológicos visando a otimização de conhecimentos e reflexões sobre práxis pastorais inovadoras em tempos de pandemia e pós pandemia. Sem esquecer do papel público da Teologia, isto é, a importância do fomento de reflexões e conhecimentos no campo da Teologia Pública com vista a ajudar governos, empresas, instituições sociais e a ciência a lidarem com temas desafiadores de sua área e que a Teologia tem contribuições a oferecer campo econômico, social, bioética, saúde e espiritualidade, religiosidade e sentido de vida, entre outros). 
A igreja pode ter ainda uma atuação profética no campo político, chamando a atenção de governos para a urgência de se atentar para o cuidado da vida nesse cenário. É momento de governos assistirem socialmente seus cidadãos vulneráveis e criar condições econômicas para a preservação da vida e empregos (FERRARI; CUNHA, 2020, n.p). É o que fazem governos humanitários e engajados na luta pela justiça. A história é rica de exemplos de superação da humanidade e retomada da economia após crises, pandemias, catástrofes, guerras, etc.

Por fim, vale destacar que a igreja que pronuncia voz profética a sociedade e suas instâncias, também é atingida pela voz profética que ela anuncia. Isso recobre-se de sentido, quando se pensa em setores da igreja e de lideranças evangélicas que nesse momento de pandemia, esquecendo-se dos valores do Evangelho, tem se orientado por princípios estritamente econômicos em seus debates e ações - por exemplo, pressionando governantes para abertura de templos (CUNHA, 2020, n.p.). A igreja em missão, que atua profeticamente na sociedade, se auto examina criticamente sempre para não fugir do Evangelho e cumprir relevantemente a missão de Deus.

\section{Considerações finais}

A Igreja é uma importante instância da representação da presença de Deus no mundo. Em tempos difíceis da humanidade, ela tem a oportunidade, a partir de suas práxis pastorais, revelar às pessoas que sofrem os sinais da compaixão e da esperança divinas: proclamar o Deus Emanuel, presente com aqueles que choram! Igualmente, a igreja tem a tarefa de revelar as intenções amorosas e redentivas de Deus, tanto para a humanidade quanto para toda a criação, impactadas pelas forças do pecado.

É verdade que essa pandemia tem trazido muito choro, mas também é uma rica oportunidade para a humanidade desenvolver seus valores nobres: amor, compaixão, solidariedade, fé e esperança. A igreja, como cooperadora na missão de Deus e orientada pelos valores do Evangelho, pode contribuir de forma significativa nesse cenário crítico que vivemos e no processo de retomada da vida pós-pandemia para a construção de um mundo/sociedade melhor!

As ferramentas virtuais têm sido uma solução importante para a igreja pastorear as pessoas nesse tempo de pandemia (Covid-19), como demostrado nessa pesquisa. Todavia, quando acontecer a flexibilização das políticas de isolamento social, enfrentaremos outras demandas e desafios pastorais. Isso exigirá da igreja e sua liderança uma leitura responsável da realidade para 
propor práxis pastorais relevante em um novo cenário: "o novo normal", distinto do período pré-pandemia.

Pode ser que nesse período de flexibilização social as pessoas procurem com euforia os cultos ou demais programações da igreja, mas também pode acontecer o inverso: insegurança e fechamento para a convivência social. $\mathrm{O}$ futuro ainda é incerto! Em todo caso, como igreja portadora de uma espiritualidade e práxis pastoral responsável, os cultos e/ou outras programações da igreja presencial nesse período deverão respeitar rigorosamente orientações do poder público para a igreja não ser um vetor de contaminação.

Além disso, como já lembrado, será importante conjugar cultos e/ou outros programações presencias com transmissão online, entre outras ações virtuais para aquelas pessoas impedidas da convivência social ou inseguras de frequentarem espaços públicos.

Esperamos que tenha gostado das reflexões apresentadas nesta pesquisa: pastoral da igreja em tempos de pandemia - Covid-19. Reconhecemos que o tema é vasto é não se esgota nas indicações aqui apresentadas. Fica o desafio e incentivo aos pesquisadores da área de Teologia Pastoral para a ampliação do assunto.

\section{Referências bibliográficas}

ALIANÇA EVANGELICA. Por que as igrejas brasileiras fecharam, apesar do presidente Bolsonaro discordar. AliançaEvangelica.org.br, 13 mar. 2020. Disponível em: < https:// aliancaevangelica.org.br/por-que-as-igrejas-brasileiras-fecharam-apesar-de-presidente-bolsonaro-discordar/ > Acesso em: 21 abr. de 2020.

BAUMAN, Zygmunt. Vida líquida. Rio de Janeiro: Zahar, 2007.

BAUMAN, Zygmunt. Medo líquido. Rio de Janeiro: Zahar, 2008.

BRANDALISE, Camila; ROVANI, Andressa. 100 dias que mudaram o mundo. UOL Universa, 9 abril 2020. Disponível em: < https://www.uol.com.br/universa/reportagens-especiais/coronavirus-100-dias-que-mudaram-o-mundo/ > Acesso em: 30 abr. 2020 BOFF, Leonardo. A importância da espiritualidade para a saúde. leonardoBoff.com, 2013. Disponível em: < https://leonardoboff.wordpress.com/2013/11/16/a-importancia-da-espiritualidade-para-a-saude/> Acesso em: 17 abr. de 2020.

CAFARDO, Renata. Casamentos são adiados por causa da pandemia do coronavírus. $O$ Estado de São Paulo, São Paulo, 28 mar. 2020. Disponível em: < https://cultura.estadao. com.br/noticias/geral,casamentos-sao-adiados-por-conta-da-pandemia-do-coronavirus, 70003251673 > Acesso em: 21 abr. de 2020.

CASTElls, M. A sociedade em rede. 6. ed. São Paulo: Paz e Terra, 2002.

CASTRO, Clovis Pinto de. Por uma fé cidadã: a dimensão pública da Igreja - fundamentos para uma Pastoral da Cidadania. São Bernardo do Campo; São Paulo: Editora da Umesp; Loyola, 2000. 
CLINEBELL, Howard J. Aconselhamento pastoral: modelo centrado em libertação e crescimento. São Paulo; São Leopoldo: Paulus; Sinodal, 1998.

COLETTA, Ricardo Della; URIBE, Gustavo. Mandetta diz que curva de transmissão do coronavírus só terá queda brusca em setembro. Folha de São Paulo, São Paulo, 20 mar. 2020. Disponível em: < https://www1.folha.uol.com.br/equilibrioesaude/2020/03/mandetta-diz-que-curva-de-transmissao-do-coronavirus-so-tera-queda-brusca-em-setembro.shtml > Acesso em: 09 de abr. de 2020.

COSTA, Gilberto. Covid-19: confinamento e distanciamento social preocupam psicólogos. EBC - Agencia Brasil; 05 abr. 2020. Disponível em: < https://agenciabrasil.ebc.com.br/ saude/noticia/2020-04/covid-19-confinamento-e-distanciamento-social-preocupam-psicologos > Acesso em: 09 abr. 2020.

COSTAS, Orlando E. El protestantismo em América Latina hoy: Ensaios Del Camino (19721974). Colecion Iglesia y Misión, 3. Costa Rica: INDEF, 1975.

CUNHA, Magali. Diante da crise do coronavírus, o que as igrejas podem fazer? Carta Capital, : 24 de mar. de 2020. Disponível em: < https://www.cartacapital.com.br/blogs/ dialogos-da-fe/diante-da-crise-do-coronavirus-o-que-as-igrejas-podem-fazer/ > Acesso em: 17 abr. 2020.

IGREJA METODISTA. A mobilização da Igreja Metodista diante da pandemia de Coronavírus. Metodista.org.br, 06 abr. 2020. Disponível em: < http://www.metodista.org.br/a-mobilizacao-da-igreja-metodista-diante-a-pandemia-de-coronavirus> Acesso em: 21 abr. 2020.

IECLB. A Igreja em tempos de coronavírus - orientações sobre o Covid-19 (Coronavírus). Nota da Presidência e de Pastores e Pastoras Sinodais (17/03/2020). Portal Luterano, 17 mar. 2020. Disponível em: < https://www.luteranos.com.br/conteudo_organizacao/ coronavirus/orientacoes-sobre-o-covid-19-coronavirus-nota-da-presidencia-e-de-pastores-e-pastoras-sinodais-17-03-2020 > Acesso em: 21 abr. 2020.

FLORISTAN, Casiano. Teologia practica: teoria y práxis la acción pastoral. Salamanca: Sígueme, 1993.

FERRARI, Andrés; CUNHA André Moreira. A pandemia de Covid-19 e o isolamento social: saúde versus economia. UFRGS, Rio Grande do Sul, 28 mar. 2020. Disponível em: < https:// www.ufrgs.br/coronavirus/base/artigo-a-pandemia-de-covid-19-e-o-isolamento-social-saude-versus-economia/ > Acesso em: 27 abr. 2020.

GADOTTI, Moacir. Perspectivas atuais da educação. São Paulo em Perspectiva, v. 14, n. 2, p. 3-11, 2000.

GONTIJO, Joana. Covid-19 faz com que pais separados adaptem a relação pelos filhos. O Estado de Minas Gerais, 18 abr. 2020. Disponível em : < https://www.em.com.br/app/ noticia/gerais/2020/04/18/interna_gerais,1139813/covid-19-faz-com-que-pais-separados-adaptem-a-relacao-pelos-filhos.shtml > Acesso em: 21 abr. 2020.

KOVÁCS, Maria Julia. Comunicação nos programas de cuidados paliativos: uma abordagem multidisciplinar. In: PESSIN, Leo; BERTACHINI, Luciana (Orgs.). Humaniz̧ação e Cuidados paliativos. São Paulo: Loyola, 2004.

LAUDENIR, Antonio. Tempos de ouvir: a importância da música no isolamento. Diário do Nordeste, 27 abr. 2020. Disponível: < https://diariodonordeste.verdesmares.com.br/ 
editorias/verso/tempos-de-ouvir-a-importancia-da-musica-no-isolamento-1.2238921 > Acesso em: 30 abr. 2020.

LEITE, Helena. Casal separado volta a morar junto pelo bem da filha durante quarentena. Revista Pais e Filhos, 30 mar. 2020. Disponível em: < https://paisefilhos.uol.com.br/familia/casal-separado-volta-a-morar-junto-pelo-bem-da-filha-durante-quarentena/ > Acesso em: 21 abr. 2020.

LIMA, Claudio Márcio Amaral de Oliveira. Informações sobre o novo coronavírus (COVID-19). Radiol Bras, São Paulo, v. 53, n. 2, 2020. Disponível em: < https://www.scielo.br/ scielo.php?script $=$ sci_arttext\&pid $=$ S0100-39842020000200001\&lng $=$ en\&nrm $=$ iso\&tlng $=$ pt $>$ Acesso em: 27 abr.2020.

LUTHER, Martin. Luther's Works. Vol. 43. Minneapolis: Fortress Press, 1968.

MIKLOS, Jorge. Ciber-religião: a construção de vínculos religiosos na cibercultura. Aparecida: Ideias \& Letras, 2012.

MINISTÉRIO DA SAÚDE. Coronavírus: linha do tempo. MS, 2020. Disponível em: < https://coronavirus.saude.gov.br/linha-do-tempo > Acesso em: 24 abr. de 2020.

NEVES, Marília. Casamentos cancelados por causa do coronavírus: choro, prejuízo e a corrida para adiar festas. O Globo, G1, 22 mar. 2020. Disponível em: < https://g1.globo.com/ pop-arte/noticia/2020/03/22/casamentos-cancelados-por-causa-do-coronavirus-choro-prejuizo-e-a-corrida-para-adiar-festas.ghtml > Acesso em: 21 abr. 2020.

OLIVEIRA, Marcio Divino; NOGUEIRA, Paulo Dias. Resiliência, fé e práxis pastoral: a igreja como agende de fé resiliente. Vox Faifae: Revista de Ciências Humanas e Letras das Faculdades Integradas da Fama, v. 2, n. 1, 2010.

OLIVEIRA, João José. Entrevista: os desafios das empresas brasileiras com a pandemia. UOL, Notícias da redação, 7 abr. 2020. Disponível em: < https://economia.uol.com.br/ noticias / redacao/2020/04/07/ nada-vai-ser-como-antes-depois-do-novo-coronavirus-diz-luiza-trajano. htm?cmpid=copiaecola > Acesso em: 9 abr. 2020a.

OLIVEIRA, Sibele. Medo da pandemia de covid-19 afeta a saúde emocional: como lidar melhor. Uol.com.br, 01 abr. 2020. Disponível em: < https://www.uol.com.br/vivabem/noticias/redacao/2020/04/01/medo-da-pandemia-de-covid-19-afeta-a-saude-emocional-como-lidar-melhor.htm > Acesso em: 17 abr. 2020b

PAES, Cintia. Coronavírus: famílias sofrem por falta de velórios de entes que morreram durante isolamento. Rede Globo Minas, 07 abr. 2020. Disponível em: < https://g1.globo. $\mathrm{com} / \mathrm{mg} / \mathrm{minas}$-gerais/noticia/2020/04/07/coronavirus-familias-sofrem-por-falta-de-velorios-de-entes-que-morreram-durante-isolamento.ghtml > Acesso em: 07 abr. 2020.

PAULA, Blanches de. Corpos enlutados: apontamentos para o cuidado pastoral. Caminhando, São Bernardo do Campo, v. 15, n. 1, p. 119-126, 2010.

PINHEIRO, Chloé. Coronavírus: novos dados sobre grupos de risco. Revista Saúde, 31 mar. 2020, Disponível em: < https://saude.abril.com.br/medicina/coronavirus-novos-dados-sobre-grupos-de-risco/ > Acesso em: 09 abr. 2020.

RAMOS, Luiz Carlos. Culto e entretenimento na sociedade do espetáculo. Caminhando, São Bernardo do Campo, v. 15, n. 2, p. 180-188, 2010.

SATHLER-ROSA, Ronaldo. Cuidado pastoral em tempos de insegurança: uma hermenêutica teológico-pastoral. São Paulo: Aste, 2004. 
SAVIANO, Murilo. Podcast isso é fantástico - Coronavírus: podemos confiar nos números? Globo.com, G1, 26 abr. 2020. Disponível em: < https://audioglobo.globo.com/g1/podcast/feed/651/isso-e-fantastico > Acesso em: 26 abr. 2020.

SILVA, André Luiz Reis da. Bolsonaro e o coronavirus: o custo do isolamento diplomático num momento de crise. Rio Grande do Sul: FCE/UFRGS. Disponível em: <https://www. ufrgs.br/fce/bolsonaro-e-o-coronavirus-o-custo-do-isolamento-diplomatico-num-momento-de-crise/ > Acesso em: 28 abr. 2020.

SCHNEIDER-HARPPECHT, Christoph. Teologia prática: no contexto da América Latina. São Paulo; São Leopoldo: Aste; Sinodal, 1998.

SCHMIDT, Beatriz; CREPALD, Maria Aparecida; BOLZE, Simone Dill Azeredo; NEIVA-SILVA, Lucas; DEMENECH, Lauro Miranda. Impactos na saúde mental e intervenções psicológicas diante da pandemia do novo coronavírus (COVID - 19). Revista Estudos de Psicologia, Campinas, v. 16, n. 4, p. 1-26, 2020. [DOI: 10.1590/SciELOPreprints.58]

SPONCHIATO, Diogo. Pesquisa mostra o grau de medo e tensão dos brasileiros com o coronavírus. Revista Saúde, 08 abr. 2020. Disponível em: < https://saude.abril.com.br/mente-saudavel/medo-e-tensao-brasileiros-coronavirus/ > Acesso em: 09 abr. 2020.

SOUPIN, Elisa. Gestantes e puérperas entram no grupo de risco para a covid-19 - entenda. Uol, Universa, 09 mar. 2020. Disponível em: < https://www.uol.com.br/universa/ noticias/redacao/2020/04/09/gestantes-e-puerperas-entram-no-grupo-de-risco-para-a-covid-19-entenda.htm > Acesso em: 27 abr. 2020.

UOL. Papa homenageia padres que morreram consolando doentes de Covid-19. UOL, Cidade do Vaticano, 09 abr. 2020. Disponível em: < https://noticias.uol.com.br/ultimas-noticias/afp/2020/04/09/papa-homenageia-padres-de-morreram-consolando-doentes-de-covid-19.htm > Acesso em: 09 abr. 2020.

VENAGLIA, Guilherme. Brasil registra mais 428 mortes por Covid-19 e número de vítimas passa de 6 mil. CNN Brasil, 01 maio 2020. Disponível em < https://www.cnnbrasil. com.br/saude/2020/05/01/brasil-registra-mais-428-mortes-por-covid-19-e-numero-de-vitimas-passa-de-6-mil > Aceso em : 01 maio 2020.

VIEIRA, P. R.; GARCIA, L. P.; MACIEL, E. L. N. Isolamento social e o aumento da violência doméstica: o que isso nos revela? Revista Brasileira de Epidemiologia, v. 23, 2020. [E200033]. Disponível em < https://blog.scielo.org/wp-content/ uploads/2020/04/1980-5497-rbepid-23-e200033.pdf > Acesso em: 17 de abr. de 2020

VIVABEM. Tire as principais dúvidas sobre covid-19, doença causada pelo coronavírus. Uol, Vivabem, 28 abr. 2020 Disponível em: < https://www.uol.com.br/vivabem/noticias/ redacao/2020/01/25/tire-suas-principais-duvidas-sobre-o-coronavirus-que-se-espalha-pelo-mundo.htm?cmpid=copiaecola $>$ Acesso em: 30 abr. 2020.

Submetido em: 30-4-2020

Aceito em: 8-5-2020 